\title{
Counselling in social work: A legitimate role?
}

\author{
Petro Booysen and Barbara Staniforth University of Auckland, Aotearoa New Zealand
}

\begin{abstract}
INTRODUCTION: Social work roles can sometimes be considered to sit on a continuum between a community work/social change perspective and a therapeutic work perspective. One perspective could be preferred above the other, at a particular time and in a particular context, or both perspectives could be supported. This article explores the legitimate function of counselling in social work in Aotearoa New Zealand.

METHODS: Data were obtained sequentially through 16 in-depth interviews and four focus groups in a qualitative $\mathrm{PhD}$ study. The respondents were practising social workers from various ethnicities and fields of practice represented in Aotearoa New Zealand. Both the interview and focus group data were analysed using a general inductive and thematic data analysis method.

FINDINGS: The data demonstrate a relationship between counselling and social work, that social workers regularly use counselling skills and that social workers have a need to develop their clinical skills. Rigid boundaries between the two professions can have adverse effects for clients at times when multi-skilled professionals are needed; participants in this study are calling for ethicality and accountability in this regard.
\end{abstract}

CONCLUSION: The findings from the data confirm the legitimacy of counselling in social work and have implications for social work practice, education, and continued professional development.

KEYWORDS: counselling, social work, therapeutic social work, clinical social work, micro skills, casework

AOTEAROA

NEW ZEALAND SOCIAL WORK 29(1), 16-27.

CORRESPONDENCE TO: Petro Booysen petrobooysen@gmail.com
The role of counselling in social work practice has sometimes been contentious. Roles within social work have often been presented along a continuum and, in many countries, social work has evolved favouring either a community work/social change perspective or a therapeutic work perspective. More recently, there has been an apparent shift towards supporting both perspectives in social work practice (Connolly \& Harms, 2009, 2011, 2013; Healy, 2012; Maidment \& Egan, 2009; Payne, 2014; Staniforth, 2010a; Staniforth, Fouché, \& O’Brien 2011).

In describing this both/and stance Connolly and Harms (2013) point out that this aspect is characteristic of social work: "A distinguishing feature of social work as one of the 'helping professions' is the emphasis on micro and macro change [emphasis in original]" (p. 14). Healy (2012) affirms that micro (work with individuals), mezzo (work with families and groups) and macro (community, policy, and organisational change work) practice are all part of professional social work practice. The commentary notes on the 2014 Global Definition of Social Work, regarding core mandates, state that social work intervention responds to the need of the individual, family, group, community, or society. In relation to social work practice, these 
notes further include, "Social work practice spans a range of activities including various forms of therapy and counseling, group work, and community work; policy formulation and analysis; and advocacy and political interventions" (IFSW, 2014, para. 15). Connolly and Harms (2013) moreover, note that social workers will choose their area of practice according to their interest, skills, and values.

This article aims to highlight counselling in social work in Aotearoa New Zealand as a legitimate function of social work. This is done through a review of previous literature and presenting data obtained from qualitative interviews and focus groups with practising social workers in Aotearoa New Zealand.

\section{Literature}

\section{Counselling skills in social work}

The debate regarding the legitimacy of counselling in social work is certainly not a new one. Younghusband (1981) refers to tensions in this regard as early as the 1900s and Brearley (1995) writes that she recalls controversy around this aspect when the term counselling (in contrast to casework) became more widely used in social work in Britain in the mid-1960s.

Payne (2014) and Dominelli (2009) have, in their quest to define the role of social workers, categorised three main types of social work. Payne identified empowerment, problem solving, and social change and Dominelli identified maintenance, therapeutic, and emancipatory. Both authors have indicated therapeutic work (to effect change) with individuals or families, as one of the key aspects of the social work role. Asquith, Clark, and Waterhouse (2005) summarised the main roles in social work. They identified these roles as counsellor or caseworker, advocate, partner, assessor of risk and of need, care manager, and agent of social control. Hence, they also listed counselling work as one of the main parts of the social worker's role and referred to assisting clients in achieving change as a key social work task.

The literature supports the legitimacy of counselling as a function of social work practice and numerous textbooks specifically teaching counselling skills for social workers, are available (Brandell, 2014; Miller, 2012; Riggall, 2012; Seden, 2005). These authors have all written about, and underlined the importance of, counselling competence and proficiency in social work practice. Hill, Ford, and Meadows (1990), for instance, have argued for the importance of counselling as a social work component and stressed the significance of social workers having adequate training and confidence in this regard. And Seden (1999, 2005), who advocates for counselling skill in social work practice, highlights the many circumstances and functions in social work practice that necessitate the use of counselling skills. "Counselling skills can underpin and permeate all key social work activities: assessing, acting, planning, advocating, working in organizations and developing competence to practice" (Seden, 2005, p 157).

Seden (2005) emphasises that social workers need some counselling skills to competently communicate and skilfully engage with clients. She further underlines that communication is a critical social work skill, employed in the shared understanding of thoughts, emotions, beliefs, and aspirations and in the process of facilitating goal attainment and change. Maidment and Egan (2016) describe micro skills as verbal and non-verbal communication techniques used in communication with others. These authors developed a framework for practice with individuals, families, and groups. The micro skills related to this framework are: listening, responding, using empathy, summarising, questioning, conciliation, validating, transfer, reflecting, paraphrasing, using silence, assertiveness, goal-setting, interpreting, externalising, verbal and non-verbal cues, clarifying, negotiation, prioritising, normalising, challenging, universalising, 
conflict management, affirming, using immediacy, boundary-setting, confronting and recording (p. 8). Beddoe and Maidment (2009) believe that social work practitioners should be able to use basic micro skills appropriately in practice once they have completed their social work qualification.

Still, depending on the contextual factors, the focus of social work may differ over time and from place to place (IFSW, 2014). Payne (2014) points out that social work is socially constructed. Therefore, social work, and the counselling component therein, have developed in a particular manner through particular influential aspects in Aotearoa New Zealand over time.

\section{The Aotearoa New Zealand context}

The modern profession of social work in Aotearoa New Zealand developed late compared to countries like the USA and the UK where professional social work appeared around the middle of the 1800s (McDonald, 1998). The first social work education programme in Aotearoa New Zealand was established at Victoria University in 1949 and Victoria continued to be the main social work education provider until 1976 (Nash, 1998).

Social work education influenced the development of the role of counselling in social work in Aotearoa New Zealand. In the early years of the Victoria programme, there was a significant focus on a therapeutically orientated approach to social work (McCreary, 1971; Nash, 1998). In 1976, social work programmes began at both Massey University and the University of Canterbury. The Canterbury programme had a strong clinical focus from the start and the Massey programme started with a balanced community and therapeutic orientation (Staniforth, 2010b). The clinical-community balance has evolved differently over time as further social work programmes developed.

Social work in Aotearoa New Zealand occurs through a bicultural framework and commitment, so any counselling done within social work in this country must acknowledge this. Counselling has often been perceived as a Western construct, and in some areas may not appear consistent with Māori values, for example, a focus on the individual (as is often seen in counselling), may be opposed to Māori collective values (Durie, 1985; Durie \& Hermansson, 1990). Western counselling frameworks have often not been seen by Māori as beneficial to their communities (Walsh-Tapiata, 2004). Subsequently, there are some Māori and culturally relevant counselling or therapeutic frameworks and models developed that have contributed to the counselling component in social work as well as to the profession of counselling (Durie, 2003; Rochford, 2004).

There is limited research available regarding counselling in social work in Aotearoa New Zealand. In a random telephone survey exploring the public's perception of social work and social workers in Aotearoa New Zealand, one of the findings in this study was that $89.6 \%$ ( $n=343$ of 383 responses to this question) of respondents believed that social workers "did counselling with people" (Staniforth, Fouché, \& Beddoe, 2014, p. 55). Apart from this, two separate Aotearoa New Zealand based studies have confirmed that many social workers in Aotearoa New Zealand experience counselling as a significant part of their social work role (Munford, 2000; Staniforth, 2010a). The Munford (2000) study found an overlap between social work and counselling skills: "The study revealed that counselling and social work practice is closely related in terms of theoretical models, skill components, value assumptions and the personal and professional qualities of practitioners" (p. 18).

Staniforth's (2010a) doctoral research used a questionnaire to explore the ideas and practice of 404 social workers in Aotearoa New Zealand in relation to counselling in social work. Results within this study included that $33 \%$ of respondents had 
counselling within their job descriptions and $96 \%$ believed that counselling fell within the role of social work in many fields of practice. A combined $62.6 \%$ of respondents indicated that they did some counselling through to the majority of their work as counselling, while 30.8\% stated that they used counselling skills in their work, but did not do counselling. Only $6.6 \%$ indicated that they did not do any counselling in their jobs. This study also found grounds for a collaborative and strength-based counselling orientation. Concepts like collaboration, inclusivity, respect, connection, and supporting people in their identity, strengths, and resources are all congruent with a strength-based orientation as well as with culturally appropriate practice (Munford \& Sanders, 2011). Various authors have agreed that a strength-based orientation is consistent with culturally appropriate practice (Eketone, 2006; Munford \& Sanders, 2011).

\section{Methodology}

Data for this article were obtained as part of a doctoral research project, which explored the question: "What are the core contextual considerations and practice components that are vital in developing and producing a practice framework for strength-based counselling in social work practice in the Aotearoa New Zealand context?" This research project obtained approval from the University of Auckland's Human Participants Ethics Committee.

Using in-depth interviews, the researcher (Booysen) explored the experience and knowledge of key stakeholders in a twophase study. In the first phase, 16 interviews were conducted, throughout the second half of 2014, with social work practitioners from various ethnicities and fields of practice who indicated expertise in strengthbased counselling (only 15 returned their transcripts with permission for the data to be used). In consultation with research supervisors, purposive sampling was used to identify potential participants who were invited to an interview. This sample was also expanded through the use of a snowball technique where interviewees were asked to identify others who might also fit the research criteria. Interviews were analysed using a general inductive and thematic data analysis method (Braun \& Clarke, 2006; Thomas, 2006).

Following on from phase one, phase two of this study presented a draft practice framework for strength-based counselling (developed in phase one), to four focus groups. Participants were recruited through inviting the phase one participants, who had indicated that they would like to be involved in a focus group, and these participants were also encouraged to invite other eligible participants. The Aotearoa New Zealand Association of Social Work (ANZASW) was also approached to invite eligible members to participate. The focus groups were conducted in October and November of 2015. While the practice framework is still in development, several themes emerged in relation to practitioners' views on counselling in social work. These are the focus of this article.

\section{Findings}

Several themes emerged in relation to counselling in social work. Themes explored here are: relatedness between counselling and social work; social work practice requires counselling skills; developing counselling skills in social work; boundaries of the professions and the effect on the counselling role in social work; and becoming multi-skilled practitioners. Participant quotes from phase one and two are used to illustrate these themes and key stakeholder interview participants are identified in the data as P1-P15. Due to the nature of focus groups, it is not always possible to identify specific individual participants from focus group transcripts and therefore the focus group participants are identified according to the group they participated in, namely "F gr 1-4." 


\section{Relatedness between counselling and social work}

Practitioners from both the interviews and focus groups discussed their views and experiences on the interrelationship between social work and counselling. Several participants indicated that they believed that the division between counselling and social work in practice is not rigid and they confirmed that there is an overlap in service delivery between social work and counselling. One participant who managed an agency employing social workers and counsellors, reported her experience in this regard:

I think even sometimes people who are trained as counsellors and social workers themselves might have a few problems in making that very clear distinction because they do cross over incredibly .... I don't know maybe $70 \%$ of the types of things that you do are similar .... But when I used to listen to, or if we did a case study where the counsellors and the social workers were there working with say a particular person, a lot of what they would talk about would be the similar sorts of things they were trying to achieve. (P10)

Another participant spoke about the tension between counselling and social work and indicated, "That tension is about 'what's social work, what's community work, what's counselling?'" (P7). He continued to point out that the strength-based approaches in practice are a particular point of interrelatedness between counselling and social work: "So I think narrative, solution focused, strength-based ways of working are probably the models and essence of what brings counselling and social work together. They are compatible models" (P7).

\section{Social work practice requires counselling skills}

During the key stakeholder interviews and focus groups, participants from several different fields of practice described there being a counselling component, requiring considerable counselling skill, in their social work role. Participant P1 articulated her experience in this regard: "So referrals might not always be for counselling but really there is a whole lot of counselling that goes into social work." A number of the participants pointed out the necessity of using counselling skills in their healthcare roles. One participant stated that, even though one might have a social work role in the healthcare environment, "usually, with any health issues there comes lots of other stuff which requires the counselling side" (P3).

Other fields of practice were also mentioned. Social work with youth and children was a field in which participants indicated that counselling skills were required. One participant found that, in her casework role, she needed counselling skills for the children she worked with. "I was employed as a caseworker but I had ... counselling kind of work with children .... So I wasn't trained as a counsellor but we used a lot of counselling tools and skills with children" (P12).

Participant P10 referred to the practitioners in the justice system who utilise counselling skills in their role. And a participant from focus group 3 added that, even in most difficult situations, for example in statutory social work, counselling skills were relevant. She noted, "the counselling you can do even when the situations are difficult—it might be with Child Youth and Family uplifting a child. It doesn't mean that you can't provide some counselling."

Furthermore, another participant from focus group 3, a community-based healthcare practitioner, who described counselling in his practice as "part of our everyday mahi" found that his counselling skills helped him to work some of the magic needed in his role. He also believed that when issues arise in a meeting, that it is part of the practitioner's daily practice and ethical responsibility to the client to respond to these. He emphasised that "it is not ok [to say] 'we'll leave that for your counsellor" in certain situations that require an adequate and immediate response from the 
practitioner. This participant further pointed out that a "window of opportunity" might be missed when the social worker does not have the skills or liberty to be able to respond to what arises for the client in that moment.

\section{Developing counselling skills in social work}

Several participants pointed out that the social work training that practitioners received, at different times and in different places, led to a workforce with varying degrees of counselling capability and varying need for further development. Practitioners who qualified overseas, for example, often experienced a different social change/therapeutic work balance in their study compared to some of their Aotearoa New Zealand qualified counterparts, as this participant indicated:

My background training is from overseas. So I have noticed the difference because a social worker in Europe is a person that does therapeutic work while here [Aotearoa New Zealand] it is looked at less. And also, for my knowledge around social work training [in Aotearoa New Zealand] it [counselling skills] is a lesser component of it really. (F gr 2)

There are also practitioners who followed a different route pertaining to their qualification and practice experience. This participant described her journey:

I started off my social work journey about 30 years ago in the UK and I trained over there. Before I trained as a psychiatric nurse because I had a mental health interest and then came over here and moved into the counselling side of social work, which I've been counselling with a bit of social work ever since. I went on to Massey to do my post grad diploma in counselling. (F gr 4)

Several participants indicated training at a time, and in a programme in Aotearoa New Zealand, when the training was based on task-focused social work with a small therapeutic component. One participant described her original social work training as well as her further professional development:

I trained many years ago and social work training was very, very task focused and very assessment focused and the therapeutic component was probably very minimal. We did some kind of "helping conversations" type of training and there wasn't that sense of social workers being in a clinical role.... But, I really believe that over time we've kind of grown into a professional role that is different and it was way after I trained that I then started training in narrative therapy and CBT, and all the other opportunities that came my way that weren't part of the curriculum when I did my training. (F gr 2)

Many other participants also found that they needed to develop their counselling skills further after completing their initial social work qualification. This participant described his experience in practice that compelled him to develop his counselling skills:

So 20 years ago I was managing a sex offender programme and had a four-year degree in social work. I'm not sure that training had given me the clinical and the therapeutic skills I needed. So I then, over four years, I completed a Master's programme in counselling. (P7)

He further pointed out that he believed it was unethical to expect practitioners to deliver a service to clients when they are under equipped for their task:

I think we do need to be teaching people the micro skills of how they work with an individual, with a family, with couples. So it is about micro skills versus social policy broad analysis and we need to work in a way that integrates that. And if we are sending practitioners out without that set of skills, we are asking them to experiment with people ... and that's probably unethical if you think about it. (P7) 
Several practitioners either reported having obtained both social work and counselling qualifications or having done additional counselling papers, courses, or workshops. The participants found their dual qualification or additional counselling training valuable in their social work practice. The participant affirmed:

I've been a social worker and I'm a counsellor as well and I've been doing that thirty years now and I've worked in refuge and prisons and sexual abuse agencies ... But I find it really valuable having both my degrees. (P6)

\section{Boundaries of the professions and the effect on the counselling role in social work}

There were participants who referred to their experience with practitioners from both the counselling and social work professions who appeared to be protective of the perceived boundaries of their professions. The earlierquoted participant who managed an agency of social workers and counsellors relayed her experience in this regard:

I noticed in that agency that counsellors were very protective of their roles and that social workers were very protective of their roles and that made it quite difficult at times when you were trying to work as a team... (P10)

Similarly, another participant who is a practice manager of a team of social workers and counsellors reflected on his experience and highlighted the uncertainty in regard to the boundaries of the social work and counselling professions that exists in practice. He described it becomes a territorial issue of "what should I do and what should I not do?" (F gr 2).

Participants also reported that social workers themselves are often hesitant to acknowledge their counselling role. One participant explained that she finds that many social workers "don't see themselves as providing counselling other than supportive counselling and they would actually defend that and be very clear that they are not counselling" (P8). She attributed this to people being careful not to imply that they are qualified as counsellors, but also thought that social workers see counselling as something separate from social work. She further noted that, even though social workers often deal with client trauma and use counselling skills in the intervention process, they would not identify this work as counselling.

A few participants added that other professionals, colleagues, and governing bodies are not always supportive of their counselling role and that this can contribute to practitioners feeling uncomfortable in acknowledging this aspect in their role. A participant revealed that it is his experience that "other agencies or professionals or registered bodies" deny the counselling role that social workers have and said, "I feel like I don't have the energy to explain" that "I did a unit or a paper on it [counselling], you just get on with it." He continued that it depends on who he talks to, as some people will simply reject the fact that he does counselling and concluded by saying "but we actually do [do counselling]" (F gr 3).

One participant cautioned that he found the rigid boundaries between the counselling and social work professions sometimes occur to the detriment of clients. He explained:

In working with pretty marginalised people virtually all of my career .... I always have felt that it's a ... very courageous step that people take, to even enter into encountering you as a professional. And so often they are adult weary because they've had poor experiences with adults in their life, and so we need to be very careful of introducing too many [practitioners] to them. (P13)

He continued that it is the norm, as a social worker, to refer people to a counselling 
service but emphasised that it may mean that a client could perhaps not make the transfer as they already have a connection and trust relationship with the social worker as opposed to the new helper:

[I've thought about] separating things into different disciplines that can work perhaps when people have selfconfidence, a strong identity. But if you are very marginalised, those things can be recipes for people dropping through the cracks when the referral is made. (P13)

\section{Becoming multi-skilled practitioners}

Participants reflected on the notion of there being less rigid boundaries between the professions and in this regard, the terms social practitioners, integrated practitioner and multi-skilled practitioners were proposed. One practitioner referred to "David Epston [who] once talked about having social practitioners." He liked that because to him it confirmed "there's something in between" the two professions (P7). The participant who cautioned earlier on rigid boundaries explained his thoughts on integrated practitioners:

Social workers might truly take on board that they can be counsellors within [their role]. I have social workers, I have counsellors, I have educationalists, and I'm trying always to get all three of those disciplines to learn from each other. And to say "you might be the one point of contact with a family, you've got to try and bring in, even if you trained as a social worker, bring your counselling, bring what you've learnt from these other practitioners, bring it into your practice because then you are truly being an integrated practitioner." (P13)

A number of participants also spoke about their hopes and ideas regarding professional development opportunities for social workers in regard to developing their counselling skills and becoming multi-skilled practitioners. Some specifically suggested that they would like to see a counselling paper as part of social work study. Most participants simply emphasised that social workers need counselling skills and that they often have a need for additional counselling training. One participant from focus group 4 said, "social work programme training could do a whole heap more around counselling." And another expressed, "I'm really interested in this because I'm quite keen to develop that therapeutic side of my social work" (F gr 4).

A number of participants felt that a social work counselling model or framework could be helpful in the process of embracing the counselling component of social work and being multi-skilled practitioners in their practice. Some indicated that a model or framework could give recognition and validation to the counselling role in social work. For instance, a participant in focus group 3 noted, "To help social workers when they practise [that they] can stand proud and say 'yes we do do' [counselling], there is a counselling component, it is recognised." Another remarked that a model or framework could be helpful in dealing with "really serious issues like the death of a child, grief and loss, [and] trauma" (P2). And others spoke about the value of a model or framework that is particularly relevant to the Aotearoa New Zealand context.

\section{Discussion and conclusions}

While the original doctoral research project focussed on exploring the question, "What are the core contextual considerations and practice components that are vital in developing and producing a practice framework for strength-based counselling in social work practice in the Aotearoa New Zealand context?", data emerged on the legitimacy of counselling in social work. Social workers indicated that counselling plays a critical role in their practice and that they require counselling skills in their regular social work roles and activities across various fields of practice. This is consistent with findings from Staniforth (2010a) and Munford (2000). 
The participants reported that there is a space in service delivery where social work and counselling overlap. The counselling component of social work and the counselling profession do not have dissimilar goals. Seden (2005) indicates that social workers need counselling skills in practice to develop competent and effective helping relationships where information and insights can be shared, and change and goal achievement can be facilitated. Whereas the definition of counselling as presented by the New Zealand Association of Counsellors (NZAC) states, "Counselling is the process of helping and supporting a person to resolve personal, social, or psychological challenges and difficulties" (NZAC, 2016, para. 1). Some fluidity between the roles and tasks of social workers and counsellors was indicated by participants in this study as well as there being some similar ways of working, for instance with strength-based approaches like solution-focused therapy and narrative therapy.

On the other hand, Seden (2005) and Munford (2000) both underline that the relationship between social work and counselling is complicated. Although the two professions share roots, theoretical frameworks, knowledge, practice skills, values and concepts, the boundaries between them are not all that clear. The participants reported a protectiveness and uncertainty surrounding the boundaries or perceived boundaries between the social work and counselling professions. They, furthermore, pointed out that the mixed messages about the legitimacy of counselling in social work contribute to uncertainty and ambiguity. Social workers are also often hesitant to acknowledge a counselling component in their role, as they are careful not to imply that they are qualified counsellors.

Notably, not all practitioners are equally well equipped with counselling skills and the social work workforce consists of practitioners with varying degrees of counselling skill capability due to people taking different qualifying routes, and qualifying in different places and at different times. Moreover, many social work practitioners indicated that they felt compelled to develop or further develop their clinical skills as they found that their basic social work qualification did not prepare them adequately in regard to the counselling skills needed in their role. Several participants in this study reported having undertaken additional workshops, papers, or courses to improve their counselling skills and a number completed both social work and counselling qualifications.

Continued professional development for supervisors is also indicated, as supervision would require social workers who do counselling to be supervised by supervisors who are qualified to do so. Although there is provision within SWRB policy for supervision to occur through others than social workers in certain cases, this would sometimes not be the first preference, and some social workers may then have to engage in supervision with a social worker as well as a clinical (counselling/therapeutic) supervisor.

These aspects point to an on-going need for initial or continued professional development in counselling training for social workers. There are potentially many different ways that training and professional development could be attained. Options indicated by participants were counselling training in undergraduate social work training programmes, a postgraduate qualification, and counselling training opportunities as further professional development for social workers. These are explored in depth elsewhere (Staniforth \& Booysen, 2016).

Research participants in this research also indicated that the development of contextually appropriate models or frameworks would be helpful to recognise and validate counselling in social work 
and support practitioners. Contextually appropriate social work, including its counselling component, in Aotearoa New Zealand is committed to bicultural practice and the principles of the Treaty of Waitangi. The strength-based approaches, referred to earlier, like solution-focused therapy and narrative therapy, are aligned with culturally appropriate practice (Eketone, 2006; Munford \& Sanders, 2011). Bertolino (2010) states that "cultural competence is a cornerstone of a strengthsbased philosophy" (p. 46) and Jones-Smith (2014) affirms that culturally competent practice is a vital part of strength-based counselling. These are non-pathologising, respectful, and collaborative ways of working which adhere to the principles of socially just practice and lead practitioners to consider the social, economic, and political systems that disadvantage people (McCashen, 2010).

These are interesting times for counselling and social work, and counselling within social work. At this time there is no mandatory registration for either counsellors or social workers in Aotearoa New Zealand. This means that there is no absolute regulation regarding "who does what?", or "who can call themselves what?" There is also little clarity over competency of social workers doing counselling in Social Work Registration Board policies, with little guidance to be found in either social work competency standards (SWRB, 2016) or qualifying programme graduate profile requirements within the Process for Recognition/ Re-Recognition of Social Work Qualifications in New Zealand policy guidelines (SWRB, 2013).

Social workers in this study indicated they do counselling. The scopes of practice are, however, not easy to delineate and mandatory registration may change that environment and bring clarity to what is required of practitioners regarding counselling skills, for example, clinical social work as in the USA which has a clear pathway. While this may provide greater clarity or endorsement of counselling as a legitimate skill within social work, there is also the possibility that it could bring greater rigidity or it could preclude this as a social work role. Rigid boundaries between the professions could, at times, be to the disadvantage of clients in that intervention opportunities could be missed and clients could be lost as they may not transfer in the referral process. A possibility of greater flexibility that came out of this research project was indicated with reference to terms like social practitioners, integrated practitioners, and multi-skilled practitioners referring to interdisciplinary and transdisciplinary practice. Silos are seldom erected to the advantage of people using social services.

This study was exploratory and the findings reported here cannot be generalised to other groups due to its small scale. A larger scale qualitative study may be beneficial to produce a generalisable result. To ensure competent service delivery, an exploration of the required social work practice competencies regarding the counselling component in social work as well as a study investigating best training options to meet these counselling practice competencies are recommended. It would also be advantageous to learn what the different schools of social work in Aotearoa New Zealand are currently teaching regarding counselling skills and how the professional boundary aspects are managed.

Increased attention to the legitimate role of counselling in social work would improve accountability and competence in this regard and serve both clients and practitioners. It is the hope of the authors that this article will contribute to support for, and acknowledgement of, social workers in their counselling activities and may further add to the debate around the legitimacy of counselling in social work. 


\section{References}

Asquith, J., Clark, C., \& Waterhouse, L. (2005). The role of the social worker in the $21^{\text {st }}$ century. Retrieved from http://www.gov.scot/resource/doc/47121/0020821.pdf

Beddoe, E., \& Maidment, J. (2009). Mapping knowledge for social work practice: Critical intersections. South Melbourne, VIC: Cengage Learning.

Bertolino, B. (2010). Strengths-based engagement and practice: Creating effective helping relationships. Boston, MA: Allyn \& Bacon.

Brandell, J. (2014). Essentials of clinical social work Thousand Oaks, CA: SAGE.

Braun, V., \& Clarke, V. (2006). Using thematic analysis in psychology. Qualitative Research in Psychology, 3(2), 77-101. http://dx.doi.org/10.1191/1478088706qp063oa

Brearley, J. (1995). Counselling and social work. Bristol, England: Open University Press.

Connolly, M., \& Harms, L. (Eds.). (2009). Social work: Contexts and practice ( $2^{\text {nd }}$ ed.). South Melbourne, VIC: Oxford University Press.

Connolly, M., \& Harms, L. (Eds.). (2011). Social work from theory to practice. Cambridge, England: Cambridge University Press.

Connolly, M., \& Harms, L. (Eds.). (2013). Social work: Contexts and practice ( $3^{\text {rd }}$ ed.). South Melbourne, VIC: Oxford University Press.

Dominelli, L. (2009). Anti-oppressive practice: The challenges of the twenty-first century. In R. Adams, L. Dominelli, \& M. Payne (Eds.), Social work: Themes, issues and critical debates ( $3^{\text {rd }}$ ed., pp. 49-64). Basingstoke, England: Palgrave Macmillan.

Durie, M. (1985) Counselling Mãori people. Paper presented at the New Zealand Counselling and Guidance Association Hui, Tu Tangata Urban Marae, Palmerston North.

Durie, M. (2003). Paiheretia: An integrated approach to counselling. In Nga kahui pou: Launching Māori futures (pp. ??-??). Wellington, NZ: Huia.

Durie, M., \& Hermansson, G. (1990). Counselling Māori people in New Zealand Aotearoa. International Journal for the Advancement of Counselling, 13(2), 107-118. http://dx.doi.org/10.1007/BF00115706

Eketone, A. (2006). Tapuwae: A vehicle for community change. Community Development Journal, 41(4), 467-480. Retrieved from http://dx.doi.org/ $10.1093 / \mathrm{cdj} / \mathrm{bsl028}$

Healy, K. (2012). Social work methods and skills: The essential foundations of practice. Houndmills, England: Palgrave Macmillan

Hill, M., Ford, J., \& Meadows, F. (1990). The place of counselling in social work. Practice, 4(3), 156-172. http://dx.doi.org/10.1080/09503159008416892

International Federation of Social Work. (2014). Definition of social work. Retrieved from http://ifsw.org/get-involved/ global-definition-of-social-work/

Jones-Smith, E. (2014). Strengths-based therapy: Connecting theory, practice, and skills. Thousand Oaks, CA: SAGE.

Maidment, J., \& Egan, R. (Eds.) (2009). Practice skills in social work and welfare: More than just common sense ( $2^{\text {nd }}$ ed.). Crows Nest, NSW: Allen \& Unwin.
Maidment, J., \& Egan, R. (Eds.). (2016). Practice skills in social work \& welfare: More than just common sense ( $3^{\text {rd }}$ ed.). Crows Nest, NSW: Allen \& Unwin.

McCashen, W. (2010). The strengths approach: A strengthsbased resource for sharing power and creating change. Bendigo, VIC: St Luke's Innovative Resources.

McCreary, J. (1971). The School of Science: Part one-The Martians. The New Zealand Social Worker, 7(1), 9-17.

McDonald, D. (1998). Social work in Aotearoa New Zealand: An introduction. Auckland, A/NZ: Addison Wesley Longman.

Miller, L. (2012). Counselling skills for social work ( $2^{\text {nd }}$ ed. $)$. Los Angeles, CA: SAGE.

Munford, G. (2000). Counselling and social work perspectives. Unpublished Research Project, Massey University, Palmerston North, New Zealand.

Munford, R., \& Sanders, J. (2011). Embracing the diversity of practice: Indigenous knowledge and mainstream social work practice. Journal of Social Work Practice, 25(1), 63-77. http://dx.doi.org/10.1080/02650533.2010.532867

Nash, M. (1998). People, policies and practice. Social work Education in Aotearoa/New Zealand from 1949-1995 (Unpublished doctoral dissertation). Massey University, Palmerston North, New Zealand.

New Zealand Association of Counsellors. (2016). What is counselling? Retrieved from http://www.nzac.org.nz/ what_is_counselling_.cfm

Payne, M. (2014). Modern social work theory (4 $4^{\text {th }}$ ed.) Chicago, IL: Lyceum Books.

Riggall, S. (2012). Using counselling skills in social work (Transforming social work practice). Los Angeles, CA: Learning Matters.

Rochford, T. (2004). Whare tapa wha: A Māori model of a unified theory of health. Journal of Primary Prevention, 25(1), 41-57.

Seden, J. (1999). Counselling skills in social work practice. Philadelphia, PA: Open University Press.

Seden, J. (2005). Counselling skills in social work practice [Ebrary version]. Retrieved from http://www.ebrary.com

Staniforth, B. (2010a). Past present and future perspectives on the role of counselling in social work in Aotearoa New Zealand (Unpublished doctoral dissertation). Massey University, Auckland, New Zealand.

Staniforth, B. (2010b). Counselling in social work in Aotearoa New Zealand: The historical, political and socio-cultural evolution. Aotearoa New Zealand Social Work, 22(3), 3-14.

Staniforth, B., \& Booysen, P. (2016). Counselling training in social work in Aotearoa New Zealand. Are we there yet? Advances in Social Work and Welfare Education, 18(2), 24-38.

Staniforth, B., Fouché, C., \& Beddoe, L. (2014). Public perception of social work and social workers in Aotearoa New Zealand. Aotearoa New Zealand Social Work, 26(2/3), 48-60.

Staniforth, B., Fouché, C., \& O’Brien, M. (2011). Still doing what we do: Defining social work in the $21^{\text {st }}$ century. Journal of Social Work, 11(2), 191-208. http://dx.doi. org/10.1177/1468017310386697

Social Workers Registration Board. (2013). The process for recognition/re-recognition of social work qualifications 
in New Zealand. Wellington, New Zealand: Author. Retrieved from http://www.swrb.govt.nz/doc-man/ policies-1/292-programme-recognition-standards-3

Social Workers Registration Board. (2016). Competence. Wellington, New Zealand: Author. Retrieved from http://www.swrb.govt.nz/doc-man/policies-1/320competence-4

Thomas, D. (2006). A general inductive approach for analyzing qualitative evaluation data. American Journal of Evaluation, 27(2), 237-246.

Walsh-Tapiata, W. (2004). The past the present and the future: The New Zealand indigenous experience of social work. Social Work Review, 16(4), 30-37.

Younghusband, E. (1981). The newest profession: A short history of social work. London, UK: Community Care/IPC Business Press. 